\title{
PENGEMBANGAN MACROMEDIAFLASH 8 PROFESSIONAL BERBASIS KARAKTER CINTA TANAH AIR SUBTEMA KEBERAGAMAN BUDAYA BANGSAKU BAGI SISWA KELAS IV SD
}

\author{
Dewi Prabasari, Vera Yuli Erviana \\ UNIVERSITAS AHMAD DAHLAN \\ dewiprabasari15@gmail.com
}

\begin{abstract}
The aim of this study; 1) to find out the steps to develop MacromediaFlash 8 Professional Based on the Character of Love of the Motherland in My Cultural Diversity Subtema for 4th grade students; 2) To find out the feasibility of MacromediaFlash 8 Professional Based on Land Love; 3) To find out student responses and teacher assessments of the quality of MacromdiaFlash 8 Professional that was developed. This study is a development research using the ADDIE development model (Analysis, Design, Development, Implementation, Evaluation). The research subjects were class IV C students in a small group trial of 10 students and class IV B students in a large group trial. Techniques for collecting expert data collection (media experts, learning experts, material experts), on product trials using teacher assessment questionnaires and student responses as suggestions and input for the feasibility of MacromediaFlash 8 Professional Based on Love Characters Homeland that researchers developed. The results of the study showed that the assessment of media experts received a 77.7 score in the category "Eligible". Assessment of learning experts received a score of 86.5 with the category "Very Worthy". The assessment of material experts scored 81.6 with the "Very Worthy" category. In evaluating product trials (small groups) scored 91.85 in the "Very Worthy" category. In the assessment of usage trials (large groups) scored 91.60 in the "Very Worthy" category. The conclusion of this study is that the media developed includes the appropriate categories of use.
\end{abstract}

Keywords: MacromediaFlash 8 Professional, national love character, diversity of my national culture. fourth grade elementary school

\begin{abstract}
ABSTRAK
Penelitian ini bertujuan; 1) untuk mengetahui langkah-langkah pengembangan MacromediaFlash 8 Professional Berbasis Karakter Cinta Tanah Air Pada Subtema Keberagaman Budaya Bangsaku bagi siswa kelas IV SD; 2) Untuk mengetahui kelayakan MacromediaFlash 8 Professional Berbasis Cinta Tanah; 3) Untuk mengetahui respon siswa dan penilaian guru terhadap kualitas MacromdiaFlash 8 Professional yang dikembangkan. Penelitian ini adalah penelitian pengembangan menggunakan model pengembangan ADDIE (Analysis, Design, Development, Implementation, Evaluation). Subjek penelitian adalah siswa kelas IV C uji coba kelompok kecil sebanyak 10 siswa dan siswa kelas IV B uji coba kelompok besar. Teknik pengumpulan data penilaian ahli (ahli media, ahli pembelajaran, ahli materi), pada uji coba produk menggunakan angket
\end{abstract}


penilaian guru serta respon siswa sebagai saran dan masukan untuk kelayakan MacromediaFlash 8 Professional Berbasis Karakter Cinta Tanah Air yang peneliti kembangkan. Hasil penelitian menunjukan bahwa penilaian ahli media mendapatkan nilai 77,7 dengan kategori "Layak". Penilaian ahli pembelajaran mendapatkan nilai 86,5 dengan kategori "Sangat Layak". Penilaian ahli materi mendapatkan nilai 81,6dengan kategori "Sangat Layak". Pada penilaian uji coba produk (kelompok kecil) mendapatkan nilai 91,85 dengan kategori "Sangat Layak". Pada penilaian uji coba pemakaian (kelompok besar) mendapatkan nilai 91,60 dengan kategori "Sangat Layak". Kesimpulan penelitian ini yaitu media yang dikembangkan termasuk kategori layak digunakan.

Kata kunci: MacromediaFlash 8 Professional, karakter cinta tanah air, keberagaman budaya bangsaku. kelas IV Sekolah Dasar

\section{PENDAHULUAN}

Pendidikan sebuah persoalan yang khas dalam kehidupan manusia. Pendidikan di indonesia tidak hanya pendidikan formal saja,tetapi juga pendidikan informal dan non formal. Dalam suatu negara pendidikan sangat berpengaruh terhadap kemajuan negara tersebut jika negara tersebut merupakan negara yang maju terdapat beberapa faktor yang mendukung kemajuan tersebut salah satunya adalah bidang pendidikan,negara yang maju memliki potensi sumber daya alam yang baik terutama pada ilmu pedidikannya.

Pedagogik atau ilmu pendidikan ialah ilmu pengetahuan yang menyelidiki, merenungkn tentang gejala-gejala perbuatan mendidik (Purwanto, 2011:33), pedagogik sangat berpengaruh dalam proses pengetahuan karena suatu proses dalam hal menyelidiki, merenungkan tentang gejala perbuatan mendidik. Dalam hal ini mendidik bukan hal yang mudah terdapat proses-proses dan harus peka dengan gejala-gejala perbuatan. Pendidikan bagi kehidupan umat manusia merupakan kebutuhan mutlak yang harus dipenuhi sepanjang hayat. Tanpa pendidikan sama sekali mustahilsuatu kelompok manusia dapat hidup berkembang sejalan dengan aspirasi untuk maju, sejahtera dan bahagia menurut konsep pandangan hidup mereka.

Menurut penelitian Marzuki (2011: 33-34), bahawa salah satu hal yang penting yang perlu diperhatikan dalam rangka pembinaan karakter yang efektif di sekolah adalah melibatkan semua mata pelajaran dan semua guru. Pengintegrasian dalam setiap matapelajaran perlu dilakukan sebab, pendidikan karakter yang dikembangkan dalam lingkungan pendidikan akan memiliki dampak langsung terhadap prestasi belajar.

Pendidikan karakter sangat perlu diatanamkan sejak usia sekolah dasar, dimana guru sebagai fasilitator dapat menjadi fasilitas bagaima menanamkan rasa cinta tanah air kepada peserta didik, pendidikan karakter dapat diintegrasikan dalam pembelajaran. Skiner dalam (Dimyati dan Mudjiono, 2010: 9) menyatakan bahwa belajar adalah suatu perilaku. Pada saat orang belajar, maka responsnya menjadi lebih baik, sebaliknya bila ia tidak belajar belajar maka responsya menurun. Ketika orang belajar akan mengalami sebuah perubahan perilaku dari yang belum tahu dengan belajar mereka menjadi tahu dan diiringi dengan perubahan perilaku mereka sendiri, sedangkan belajar juga adalah suatu proses yang dilakukan individu untuk memperoleh suatu perubahan tingkah laku yang baru secara keseluruhan ,sebagai hasil pengalaman individu itu sendiri di dalam interaksi dengan lingkunganya (Aunurrahman, 2014: 35).

Salah satu alternatif yang dapat dilakukan agar pembelajaran dapat maksimal yaitu degan menggunakan media pembelajaran. Hamalik (2013:23) berpendapat bahwa media pendidikan adalah alat, metode, teknik yang dapat digunakan dalam rangka lebih mengkomunikasikan interaksi antara guru dan siswa dalam proses pendidikan dan 
pengaaran di kelas. Kata media berasal dari bahasa Latin medius yang secara harfiah berarti 'tengah', 'perantara'atau 'pengantar'.Media pembelajaran dapat membantu guru dalam pembelajaran di kelas memudahkan siswa dalam belajar, mengingat karakterisitik siswa sekolah dasar yang masih senang dengan bermain, dengan konkret serta rasa ingin tahu mereka yang tinggi. Media pembelajaran adalah sebuah alat yang berfungsi dan dapat digunakan untuk menyampaikan pesan pembelajaran (Arsyad, 2016: 3).

Media pembelajaran dapat menjadi salah satu alternatif guru dalam menyampaikan materi sesuai dengan karakteristik peserta didik sekolah dasar,pemilihan media juga sangat penting yang harus diperhatikan oleh seorang guru pemilihan media pembelajaran memiliki banyak jenisnya tinggal menyesuaikan saja antara tujuan pembelajaran dengan karakteristik media tersebut. Beragam jenis media saat ini memiliki perkembangan yang sangat pesat untuk itu guru dituntut lebih kreatif dan inovatif.

Berdasarkan hasil ketika magang terapan pada tanggal 28 Agustus 2017 dan dilakukannya lagi obeservasi untuk memperkuat penelitian ini dilakukan oleh peneliti pada tanggal 28 Januari 2018, peneliti melakukan observsi dan wawancara dengan walikelas IV dan murid di kelas IV SD Muhammadiyah Karangkajen menunjukan bahwa minat siswa ketika pembelajaran tematik masih biasa saja kurang berinteraksi dengan guru dan kurangnya media interaktif yang mendukung pembelajaran di kelas, khususnya Tema Indahnya Kebersamaan, Subtema Keberagaman Budaya Bangsaku. Sehingga yang aktif ketika pembelajaran hanya guru saja. Metode yang digunakan guru hanyalah metode ceramah dan tanya jawab yang mengakibatkan guru lebih aktif dari pada siswa. Oleh karena itu, penulis tertarik untuk mengembangkan media pembelajaran berbentuk compact disk (untuk selanjutnya disebut CD) pembelajaran interaktif berbasis pendidikan karakter.

Menurut Majid (2014: 80) Pembelajaran tematik merupakan salah satu model pembelajaran terpadu (integrated instruction) yang merupakan suatu sistem pembelajaran yang memungkinkan siswa, baik secara individu maupun kelompok aktif menggali dan menemukan konsep serta prinsip-prinsip keilmuan secara holistik bermakna dan otentik. Pembelajaran tematik sebagai model pembelajaran termasuk salah satu tipe/jenis daripada model pembelajaran terpadu. Istilah pembelajaran tematik pada dasarnya adalah model pembelajaran terpadu yang menggunakan tema untuk mengaitkan beberapa pelajaran sehingga dapat memberikan pengalaman bermakna pada siswa Depdiknas (Endang, 2006:5).

Berdasarkan pendapat para ahli di atas dapat disimpulkan bahwa pembelajaran tematik merupakan salah satu model pemeblajaran terpadu yang mengintegrasikan pembelajaran yang satu dengan pembelajaran yang lain dengan sistem yang memungkinkan siswa baik secara individu maupun secara kelompok untuk menemukan konsep serta pembelajaran yang menggunakan tema untuk mengaitkan beberapa pelajaran sehingga dapat memberikan pengalaman bermakna dengan bersinggungkan kepada kehidupan sehari-hari siswa.

Pendidikan tidak hanya sekedar belajar dan mengajar tetapi dimana guru harus menanamkan karakter yang baik kepada siswa oleh karena itu dibutuhkan pendidikan karakter di sekolah. Pembinaan karater di skeolah dapat melalui mata pelajaran, dan semua guru terlibat dalam menumbuhkan pendidikan karakter di sekolah, guru dapat mengimplementasika pendidikan.

Perkembangan dari masa kanak-kanak sampai remaja mengalami perubahan dari struktur fisik dan mental, jasmani rohani sebagai ciri-ciri memasuki masa kedewasaan. Masing-masing anak memiliki karakteristik berbeda-beda satu dengan yang lain. Hal ini sesuai dengan usia dan tahapan berfikir siswa tersebut. Anak-anak usia sekolah dasar ini memiliki karakteristik yang berbeda-beda dengan anka yang usianya lebih muda, ia senang 
bermain, senang bergerak, senang bekerja dalam kelompok, dan senang merasakan atau melakukan sesuatu secara langsung (Desmita, 2014:35).

Pendidikan adalah suatu usaha yang sadar dan sistematis dalam mengembangkan potensi peserta didik. Juga merupakan suatu usaha masyarakat dan bangsa dalam mempersiapkan generasi muda bagi berlangsungnya kehidupan masyarakat dan bangsa yang baik di masa depan. Keberlansungan itu ditandai oleh pewarisan budaya dan karakter yang telah dimiliki masyarakat dan bangsa, peneliti mengangkat judul berbasis karakter cinta tanah air karena saat ini karakter menjadi urgensi di Indonesia.

Pengertian yang sederhana pendidikan karakter adalah hal positif apa saja yang dilakukan oleh guru dan berpengaruh kepada karakter siswa yang diajarnya. Menurut Fakry Gaffar dalam (Kesuma Dharma, dkk (2012: 5) pendidikan karakter adalah sebuah proses transformasi nilai-nilai kehidupan untuk ditumbuh kembangkan dalam kepribadian seseorang sehingga menjadi satu dalam prilaku kehidupan orang lain. Sedangkan menurut Muclas (2011:41) menjelaskan bahwa karaker dimaknai sebagai cara berpirik dan berperilaku yang khas tiap individu untuk hidup dan bekerjasama, baik dalam lingkungan keluarga, masyarakat, negara dan bangsa..

Macam-macam nilai dan deskripsi nilai pendidikan pudaya dan karakter bangsa, sebagai berikut: jujur, toleransi, disiplin, kerja keras, kreatif, mandiri, demokratis, rasa ingin tahu, semangat kebangsaan, cinta tanah air, menghargai prestasi, bersahabat/ komunikatif, gemar membaca, peduli lingkungan, peduli sosial, dan tanggung jawab.

Media adalah segala sesuatu yang dapat digunakan untuk menyalurkan pesan dari pengirim ke penerima sehingga dapat merangsang pikiran, perasaan, perhatian, dan minat serta perhatian siswa sedemikian rupa sehingga proses belajar terjadi (Sadiman, 2014:07). Menurut Arsyad (2015:3) Kata media berasal dari Bahasa Latin medius yang secara harfiah berarti 'tengah, 'perantara' atau 'penyalur'. Dalam Bahasa Arab, media adalah perantara atau pengantar pesan dari pengirim ke penerima pesan. Garlach dan Ely (1971) dalam Rostina Sundayana (2015:4) menyatakan bahwa media apabila dipahami secara garis besar adalah manusia, materi atau kejadian yang membangun kondisi yang membuat siswa mampu memperoleh pengetahuan, ketrampilan, atau sikap.

MacromediaFlash 8 adalah software aplikasi untuk animasi yang digunakan untuk internet. Program MacromediaFlash 8 merupakan program yang paling flexibel dalam pembuatan animasi, seperti animasi interaktif, game, company profile, persentasi, movie, dan tampilan animasi lainnya (Sutopo,2003: 60). Sedangkan pengertian macromediaflash yang lainnya juga dijelaskan oleh Madcom (2004: 1) macromediaflash adalah sebuah program animasi yang telah banyak digunakan oleh para desainer untuk menghasilkan desain yang professional. MacromediaFlash 8 memiliki keunggulan dibanding program lain yang sejenis, antara lain :

a) Dapat membuat tombol interaktif dengan sebuah movie atau objek yang lain.

b) Dapat membuat perubahan transparansi warna dalam movie.

c) Membuat perubahan animasi dari satu bentuk kebentuk lain.

d) Dapat membuat gerakan annimasi dengan mengikuti alur yang telah ditetapkan

e) Dapat dikonversi dan dipublikasikan (Publish) ke dalam beberapa tipe, di antaranya. swf, .html, .gif, .jpg, .png, .exe, .mov.

Dari beberapa pendapat para ahli di atas dapat disimpulkan bahwa media pembelajaran MacromediaFlash 8 yang didesain secara sistematis dan utuh sesuai dengan kebutuhan siswa untuk mengukur suatu tujuan pembelajaran yang telah direncanakan. Selain itu MacromediaFlash 8 Professional dapat membuat pembelajran lebih interaktif dan membuat siswa lebih aktif lagi saat pembelajaran. 
Berdasarkan penjelasan permasalahan diatas, maka peneliti akan melakukan penelitian mengenai "Pengembangan MacromediaFlash 8 Professional Berbasis Karakter Cinta Tanah Air Subtema Keberagaman Budaya Bangsaku Bagi Siswa Kelas IV Sekolah Dasar". Penelitian ini diharapkan dapat mampu mempu memberikan sumbangan solusi maupun bantuan dalam menumbuhkan karakter cinta tanah air pada siswa. Selain itu penelitian ini diharapkan mampu pandangan pengetahuan guru dalam mengembangkan media pembelajaran.

\section{METODE PENELITIAN}

Model ADDIE di atas terdiri dari 5 tahapan yaitu 1) Tahap Analysis/ Analisa yaitu Analisis kebutuhan untuk menentukan masalah dan solusi yang tepat dan menentukan kompetensi siswa; 2) Design/ Perencanaan yaitu Menentukan kompetensi khusus, metode, bahan ajar, dan strategi pembelajaran; 3) Development/ Pengembangan yaitu Memproduksi program dan bahan ajar yang akan digunakan dalam program pembelajaran; 4) Implementation/ Implementasi yaitu Melaksanakan program pembelajaran dengan menerapkan design atau spesifikasi program pembelajaran; 5) Evaluation/ Evaluasi yaitu Melakukan evaluasi program pembelajaran dan evaluasi hasil belajar. Pada tahap Uji coba awal dilakukan para ahli atau dosen yaitu ahli media, ahli materi, dan ahli pembelajaran untuk mengetahui kekurangan dan kelebihan suatu produk, kelompok kecil, dan kelompok besar. Instrumen dalam penelitian ini dalam mengumpulkan data menggunakan angket, dan dokumentasi. Teknis analisis data yang digunakan untuk mengolah data yang diperoleh dalam pengembangan MacromediaFlash 8 Professional dengan menggunakan analisis kualitatif dan kuantitatif.

\section{HASIL DAN PEMBAHASAN}

Hasil penelitian modul pembelajaran oleh dosen ahli, guru dan siswa melalui uji coba produk (kelompok kecil) dan uji coba produk (kelompok besar) adalah sebagai berikut :

a. Analisis Data Ahli Media

Hasil skor dari validasi ahli media menunjukan skor 56 sehingga mendapatkan nilai 77,7. Berdasarkan kategori media pembelajaran mendapatkan kategori "Baik". Selain melakukan penilaian ahli memberikan komentar dan saran untuk MacromediaFlash 8 Professional berbasis karakter cinta tanah air yang peneliti kmbangkan. Hal ini bertujuan agar modul pembelajaran layak digunakan pada saat proses pembelajaran. Komentar dan saran yang diberikan oleh ahli media sebagai berikut :

1) Pada halaman awal perlu diberikan musik agar lebih menarik tidak sekedar judul saja.

2) Pada materi Bahasa Indonesia belum jelas nya mengenai kalimat yang menunjukan sebagai gagasan utama dan gagasan pendukung.

3) Belum adanya tampilan vidio pada media yang menjelaskan macam - macam alat musik dan cara memainkanya.

4) Pada latihan soal dan quiz harus memilih salah satu diantaranya ditampilkan pada media.

b. Analisis Data Ahli Pembelajaran

Hasil skor dari validasi ahli pembelajaran menunjukan skor 45 sehingga mendapatkan nilai 86,5. Berdasarkan kategori media pembelajaran mendapatkan kategori "Sangat Baik". Selain melakukan penilaian ahli memberikan komentar dan saran untuk MacromediaFlash 8 berbasis karakter cinta tanah air yang peneliti 
kmbangkan. Hal ini bertujuan agar modul pembelajaran layak digunakan pada saat proses pembelajaran. Komentar dan saran yang diberikan oleh ahli media sebagai berikut: Rencana Pelaksanaan Pembelajaran mohon lebih sederhana namun harus sesuai langkah-langkah pembelajaran yang menguatkan rasa nasionalisme atau cinta tanah air.

c. Ahli Data Ahli Materi

Hasil skor dari validasi ahli media menunjukan skor 45 sehingga mendapatkan nilai 81,5. Berdasarkan kategori media pembelajaran mendapatkan kategori "Sangat Baik". Selain melakukan penilaian ahli memberikan komentar dan saran untuk MacromediaFlash 8 Professional Berbasis Karakter Cinta Tanah Air yang peneliti kmbangkan. Hal ini bertujuan agar modul pembelajaran layak digunakan pada saat proses pembelajaran. Komentar dan saran yang diberikan oleh ahli media sebagai berikut :

1. Materi sudah bagus, namun pada tujuan pembelajaran kurang degree.

2. Pada judul materi di media harus di-space agar rapih.

3. Ditambahkan soal uraian atau isian singkat yang bersangkutan dengan materi keberagaman buda bangsaku untuk mengevaluasi siswa.

d. Analisis Data Agket Respon Siswa Pemakain Produk

Hasil skor dari validasi angket respon siswa terhadap media kelompok kecil menunjukan skor 419 sehingga mendapatkan nilai 94,2 Berdasarkan kategori media pembelajaran mendapatkan kategori "Sangat Bik" dan uji kelompok besar menunjukan skor 828 sehingga mendapatkan 94,0. Selain melakukan penilaian ahli memberikan komentar dan saran untuk MacromediaFlash 8 Professional Berbasis Karakter Cinta Tanah Air yang peneliti kembangkan. Hal ini bertujuan agar

modul pembelajaran layak digunakan pada saat proses pembelajaran. Komentar dan saran yang diberikan oleh ahli media sebagai berikut :

a) Media pembelajaran Menarik.

b) Materinya menarik.

c) Game membuat siswa semakin minat belajar.

d) Mudah dipahami.

e) Analisis Data Penialain Guru.

Hasil skor dari validasi angket penilaian guru memperoleh skor 47 mendapatkan nilai 90,3 terhadap media kelompok kecil menunjukan skor sehingga mendapatkan nilai 94,2 Berdasarkan kategori media pembelajaran mendapatkan kategori "Sangat Baik" dan uji kelompok besar menunjukan skor 45 sehingga mendapatkan 86,5. Selain melakukan penilaian ahli memberikan komentar dan saran untuk

MacromediaFlash 8 Professional Berbasis Karakter Cinta Tanah Air yang peneliti kmbangkan. Hal ini bertujuan agar modul pembelajaran layak digunakan pada saat proses pembelajaran. Komentar dan saran yang diberikan oleh ahli media sebagai berikut :

a) Dengan menggunakan alat peraga (LCD) siswa akan lebih konsentrasi.

b) Ketika pembelajaran di kelas waktu kurang efektif hanya dengan menggunakan MacromediaFlash 8Berbasis Professional Karakter Cinta Tanah air.

Tabel 25. Hasil Penilaian Para Ahli dan Uji Coba Terhadap Media

\begin{tabular}{|c|l|l|l|}
\hline No. & \multicolumn{1}{|c|}{ Penilaian } & \multicolumn{1}{|c|}{ Nilai } & \multicolumn{1}{c|}{ Kategori } \\
\hline 1. & Ahli Media & 77,7 & Baik \\
\hline 2. & Ahli Materi & 81,6 & Sangat Baik \\
\hline 3. & Ahli Pembelajaran & 86,5 & Sangat Baik \\
\hline
\end{tabular}




\begin{tabular}{|c|l|l|l|}
\hline 4. & $\begin{array}{l}\text { Uji Coba Produk } \\
\text { Kelompok Kecil }\end{array}$ & 92,25 & Sangat Baik \\
\hline 5. & $\begin{array}{l}\text { Uji Coba Pemakaian } \\
\text { Kelompok Kecil }\end{array}$ & 91,6 & Sangat Baik \\
\hline Jumlah & & 429,65 & - \\
\hline Nilai & Uji Coba & 85,93 & Sangat Baik \\
\hline
\end{tabular}

Diagram 1.

Penilaian Produk

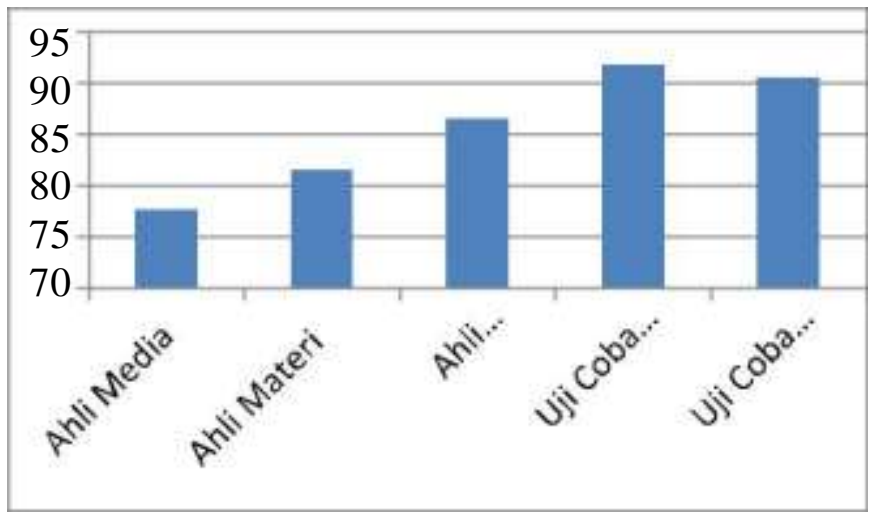

\section{SIMPULAN}

Berdasarkan hasil penelitidan pengembangan media pembelajaran Macromedia Flash 8 Professional Berbasis Karakter Cinta Tanah Air pada Subtema Keberagaman Budaya Bangsaku kelas IV SD telah berhasil digunakan dan layak dikembangkan sebagi media pembelajaran bagi siswa kelas IV SD Muhammadiyah Karangkajen IV.

\section{DAFTAR PUSTAKA}

Alkrienciehie, A. S. (2013). Pendidikan Karakater (Pendidikan Berbasia Agama dan Budaya Bangsa). Bandung: Pustaka Setia.

Arikunto, S. (2011).Prosedur Penelitian. Jakarta: Rineka Cipta.

Naim, N. (2012).Character Building. Jogjakarta: Ar Ruzz Media.

Sani, R. A. (2014). Pembelajaran Saintifik Untuk Implementasi Kurikulum 2013. Jakarta: Bumi Aksara.

Pribadi, B. A. (2009). Model Desain Sistem Pembelajaran. Jakarta: Dian Rakyat.

Arsyad, A. (2016). Media Pembelajaran. Jakarta: PT. Raja Grafindo Persada.

Asyhar, R. (2012). Kreatif Mengembangkan Media Pembelajaran. Jakarta: Referensi Jakarta.

Arismantoro. (2008). Character Building. Yogyakarta: Tiara Wacana.

Daryanto. (2013). Menyususn Modul Bahan Ajar Untuk Persiapan Guru Dalam Mengajar. Yogyakarta: Gava Media.

Mu'in, F. (2011).Pendidikan karakter. Jogjakarta: Ar-Ruzz Media.

Sugiyono. (2015).MetodePenelitian \& Pengembangan Reaserch and Development. Bandung: Alfabeta. 